\title{
MODELOS CONSTITUTIVOS DE SEQUÊNCIAS DIDÁTICAS: enfoque na Teoria das Situações Didáticas
}

\author{
Roberto da Silva Nunes ${ }^{1}$ \\ José Messildo Viana Nunes²
}

\section{RESUMO}

O objetivo deste artigo é refletir sobre o processo de construção de Sequências Didáticas, a partir de modelos teóricos da Didática Francesa, com enfoque na Teoria das Situações Didáticas. Trata-se de uma pesquisa teórica, cujas reflexões são ilustradas por noções relativas à divisibilidade. Buscamos apresentar alguns princípios que possam orientar professores e pesquisadores na construção de Sequências Didáticas. O panorama dos modelos apresentados pode se configurar como dispositivo didático para sala de aula, pesquisas científicas ou dispositivo de formação de professores. Além disso, evidenciamos que a Teoria das Situações Didáticas configura-se como modelo geral de construção de Sequências.

Palavras-chave: Sequências Didáticas. Didática da Matemática. Teoria das Situações Didáticas.

\section{CONSTITUTIVE MODELS OF DIDACTIC SEQUENCES: FocUs on Theory of Didactic Situations}

\begin{abstract}
The objective of this article is to reflect on the process of construction of Didactic Sequences from theoretical models of French didactics with focus on the Theory of Didactic Situations. It is a theoretical research whose reflections are illustrated by notions of divisibility. We seek to present some principles that can guide teachers and researchers in the construction of Didactic Sequences. The panorama of the presented models can be configured as didactic device for classroom, scientific researches or device of formation of teachers. In addition, we show that the Theory of Didactic Situations is configured as a general model of sequence construction.
\end{abstract}

Keywords: Didactic sequences. Didactics of Mathematics. Theory of Didactic Situations.

\footnotetext{
1 Professor Mestre da Secretaria de Estado de Educação do Pará (SEDUC-PA), Belém/PA. Email: robertaoeducador@hotmail.com

2 Professor Doutor do Programa de Pós-Graduação em Educação em Ciências e Matemáticas (PPGECM) do Instituto de Educação Matemática e Científica (IEMCI) da Universidade Federal do Pará (UFPA), Belém/PA. Email: messildo@ufpa.br
} 


\section{MODELOS CONSTITUTIVOS DE SECUENCIAS DIDÁTICAS: enfoque en la Teoría de las Situaciones Didácticas}

\section{RESUMEN}

El objetivo de este artículo es reflexionar sobre el proceso de construcción de Secuencias Didácticas a partir de modelos teóricos de la Didáctica Francesa con enfoque en la Teoría de las Situaciones Didácticas. Se trata de una investigación teórica cuyas reflexiones son ilustradas por nociones relativas a la divisibilidad. Buscamos presentar algunos principios que puedan orientar a profesores e investigadores en la construcción de Secuencias Didácticas. El panorama de los modelos presentados puede configurarse como dispositivo didáctico para aula, investigaciones científicas o dispositivo de formación de profesores. Además, evidenciamos que la Teoría de las Situaciones Didácticas se configura como modelo general de construcción de Secuencias.

Palabras clave: Secuencias Didácticas. Didáctica de las Matemáticas. Teoría de las Situaciones Didácticas.

\section{INTRODUÇÃO}

A noção de Sequência Didática ao longo dos anos tem se difundido nos discursos pedagógicos de formação inicial e continuada de professores, em todos os níveis, mas principalmente para os que atuam nos anos iniciais. A expansão dessa noção tem ganhado território no âmbito de pesquisas em nível de pós-graduação, mais acentuadamente nos mestrados profissionais.

Para evidenciarmos nossa assertiva, realizamos uma busca inicialmente geral no catálogo de teses e dissertações da Coordenação de Aperfeiçoamento de Pessoal de Nível Superior (CAPES), utilizando o termo Sequência Didática, referentes aos anos de 2013 a 2016 encontramos 9285 pesquisas relacionadas ao termo, na grande área Multidisciplinar aparecem 1764 trabalhos, com o refino para área de conhecimento Ensino de Ciências e Matemática e Ensino, localizamos 1302 dissertações (149 teses de doutorado, 711 dissertações de mestrado profissional e 442 de mestrado acadêmico). O gráfico 1 mostra o crescimento ano a ano de pesquisas que enfocaram a noção de Sequência Didática (Figura 1). 
Figura 1 - Gráfico da busca pelo termo Sequência Didática de 2013 a 2016

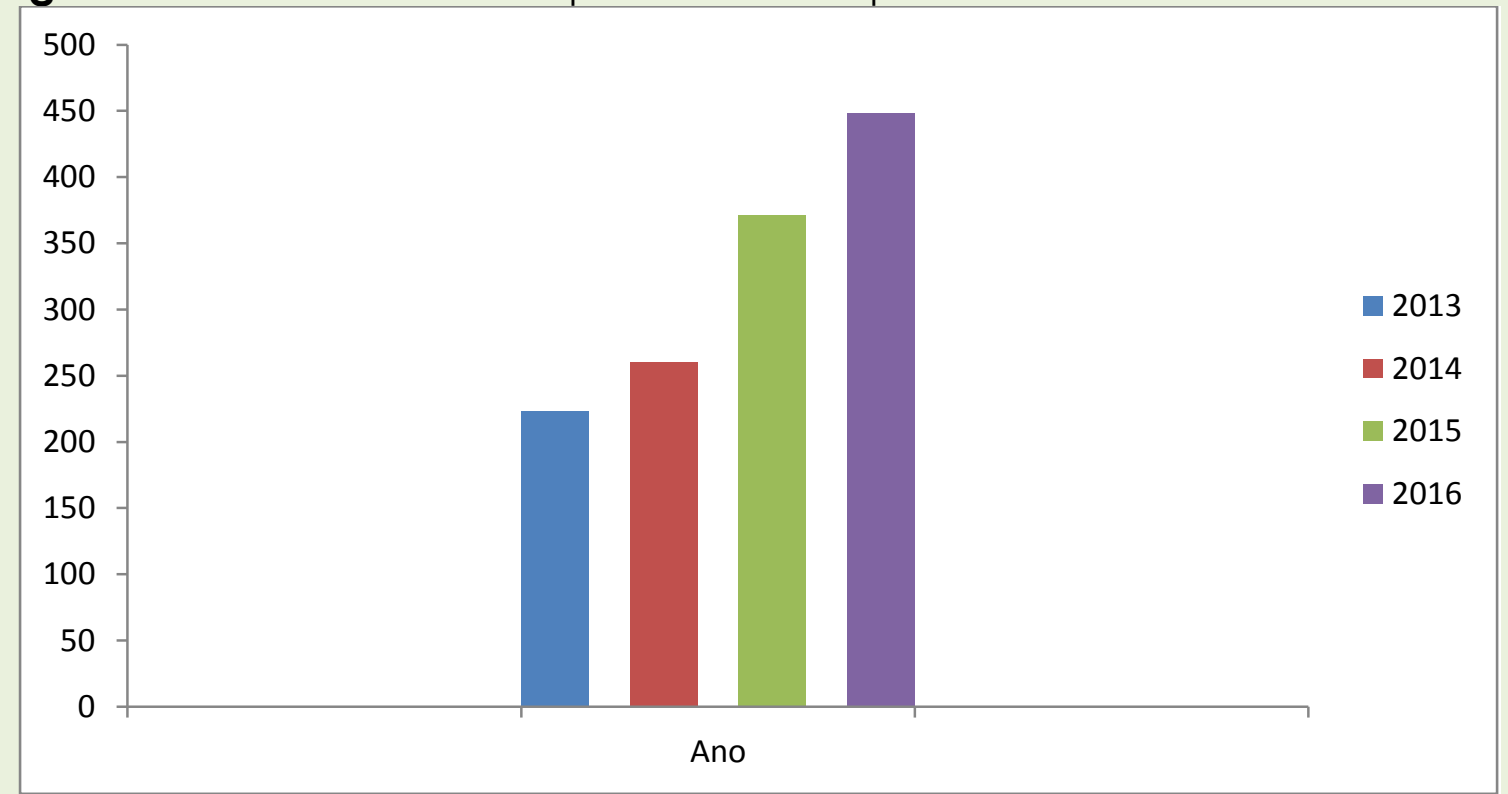

Fonte: Catálogo de teses e dissertações da CAPES

A sequência como uma prática didática traz em seu bojo muitas questões, tanto aos professores, quanto aos pesquisadores que, em geral, giram em torno do tempo necessário para seu desenvolvimento, se devem seguir uma ordem linear, qual a frequência de uso? E o principal como construílas de forma articuladas?

O tempo requerido é relativo, pois depende, entre várias questões, dos conhecimentos prévios que a turma apresenta sobre o assunto a ser tratado na sequência (pelo menos a maioria); do cumprimento dos prazos e conteúdos estabelecidos pela instituição escolar; dos objetivos do professor e/ou do pesquisador, etc. Tomando como base essas variáveis e outras inseridas na complexa relação de ensino e aprendizagem, constatamos que, em geral, as Sequências podem ser planejadas para serem desenvolvidas em uma ou mais aulas, mas podem ter caráter de projeto e ter um alcance bem maior.

Uma questão problemática na construção das sequências, refere-se a sua suposta linearidade, mas, na realidade, trata-se de um processo que apresenta recursividade e interatividade, a progressão que se impõe está relacionada à distinção entre a construção do saber-fazer e do saber, os modelos que servem a sua construção, em geral, apresentam fases por 
questão de ordem metodológica, mas não rígidas, como no caso da Teoria das Situações Didáticas (TSD), cujo modelo de construção de Sequências Didáticas, fundamenta-se nas fases de ação, formulação, validação e institucionalização e da Teoria Antropológica do Didático (TAD), cunhada por Chevallard, Bosch e Gacòn (2001), a fim de instituir um processo de estudo em sala de aula de matemática, a partir dos Momentos Didáticos: primeiro encontro; exploração do tipo de tarefas; constituição do ambiente tecnológico-teórico, relativo à técnica; trabalho com a técnica; institucionalização e avaliação. Tais modelos apresentam fases que podem ser concomitante e até mesmo ocorrer fora da ordem descrita no modelo.

Em relação à frequência, fica atrelada ao alcance que o professor e/ou o pesquisador determina, a partir de seu planejamento lem conformidade com a instituição de pesquisa ou escolar que esteja inserido), em geral, é usada para introduzir novos saberes que podem ter a dimensão de um setor, de um tema ou de um objeto, conforme elencado por Chevallard (2002).

Entendemos que, independente, dessas e de outras questões, a construção das sequências requerem que o professor e/ou o pesquisador estabeleça uma relação epistemológica com os saberes envolvidos na sequência, nos termos elencados por Brosseau (1996) e Chevallard (2009a).

A proliferação de discussões sobre Sequência Didática acarretou uma gama de concepções sobre essa noção, com duas grandes dimensões, uma estrito sensu de cunho teórico, difundia principalmente na França e na Espanha (BROUSSEAU, 1996; ASTOLFI, 1990, RICKENMANN, 1998; NOVERRAZ, 2016; ZABALA, 1998), outra lato sensu de cunho pedagógico (sem alusão explícita a modelos teóricos o que Brousseau (2006) denomina de modelo didático espontâneo), seja para concretizá-la em sala de aula ou em pesquisas científicas.

A partir do exposto neste artigo, temos o objetivo de refletir sobre como construir uma Sequência Didática, fundamentada na Perspectiva da Didática da Matemática de Influência Francesa. Para alcançar nosso objetivo desenvolvemos uma pesquisa teórica com base em obras dos 
principais estudiosos da Escola Francesa que discorreram sobre modelos teóricos para construção de Sequências. Para vislumbrar um conteúdo no processo de concepção de uma Sequência, usamos exemplos oriundos de uma pesquisa de mestrado profissional de um dos autores desse artigo que trata de números primos (NUNES, 2017).

\section{VISÃO GERAL DA NOÇÃO DE SEQUÊNCIA DIDÁTICA}

Introduzida nos anos de 1980, como elemento organizador da formação nos Liceus profissionais 3 , as Sequências Didáticas foram inseridas nos textos oficiais da Educação Nacional em vários países, mas principalmente na França, que preconizava um ensinamento organizado em sequências.

Nessa perspectiva, e de forma geral, uma Sequência Didática é uma unidade de trabalho durante a qual os alunos devem colocar em prática suas competências ${ }^{4}$ assimiladas, consolidadas, adquiridas anteriormente e não perfeitamente estabilizadas e primordialmente para aquisição de novas competências.

As Sequências organizam as disciplinas sobre um conjunto de atividades que visam fazer com que o aluno adquira certo numero de saberfazer e de saberes claramente identificados e previamente definidos; tendo como base os conhecimentos prévios dos discentes. Devem seguir um princípio de ordenação e finalidades, com objetivos precisos, planejadas em um tempo suficiente para que os aprendizes (de um determinado nível) possam realizá-las em uma ou mais aulas ou semana ou semestre, etc. Devem permitem que os alunos se apropriem de novas habilidades 5 ou no caso daqueles que já se apropriaram dessas as Sequências servirão para o

\footnotetext{
3 Via profissional da escola francesa na qual os alunos se preparam, em dois anos para adquirirem um certificado de aptidão profissional que permite entrar no mundo do trabalho ou prosseguir estudos tendo em vista um diploma de ensino secundário profissional, ou o mesmo diploma em três anos que permite, também, entrar no mundo do trabalho e prosseguir estudos.

${ }^{4}$ Conjunto de habilidades e atitudes requeridas para o exercício de uma função.

5 Capacidade de produzir um conjunto de comportamentos necessários para a realização de uma tarefa; são partes de constructos adquiridos no decorrer de diferentes aprendizagens.
} 
fortalecimento das habilidades em jogo. Uma questão primordial nesse dispositivo didático é seu potencial para efetivação de avaliação formativa6, visto que é possível acompanhar a progressão do aluno de forma confiável em termos de competências e habilidades.

Do ponto de vista estrito senso, temos modelos estabelecidos para construção das Sequências, como já destacamos anteriormente, mas as construídas para o ensino regular de sala de aula apresentam vários aspectos que a diferenciam daquelas para pesquisas, como os objetivos, dispositivo de formação e o caráter analítico. Nosso interesse maior é enfocar as construções de Sequências para pesquisa, sem deixar de lado seu desdobramento para sala de aula.

Recorrer a um modelo para conceber uma sequência, muitas das vezes não é bem vista pela comunidade científica (principalmente nos discursos pós-modernos), isso reflete tanto em pesquisas de pós-graduação, quanto no trabalho em sala de aula, pois os pesquisadores/professores sem um devido aprofundamento de campos teóricos que favorecem a construção das Sequências tendem a concebê-las - em particular no discurso pedagógico - como uma receita pronta para se aplicar cegamente, como se as Sequências fossem rígidas, sem espaços para adequações e aprimoramento para os diversos públicos alvos, sejam alunos de diferentes níveis ou como dispositivo de formação para professores em formação inicial e continuada. Além disso, há variados modelos teóricos que possibilitam a constituição das Sequências (LAURENS, 2012).

Para Laurens (2012) o recurso a um modelo favorece a articulação de atividades de ensino e aprendizagem, pois permite ao pesquisador/professor compreender a complexidade do que precisa ensinar e fazer os recortes da realidade para desenvolver um processo de estudo direcionado. Nessa perspectiva a questão é:

\footnotetext{
6 Apesar de admitirem a polissemia do termo avaliação formativa Black e Wiliam (1998) assumem que ela abrange todas as atividades realizadas pelos professores e/ou por seus alunos, que fornecem informações a serem utilizadas como feedback para modificar as atividades de ensino e aprendizagem em que estão envolvidos.
} 
Podemos agir sem um modelo, isto é, sem uma ferramenta que nos permita entender a realidade? O que faríamos se não pudéssemos selecionar algumas informações relevantes, de uma gama de estímulos que nos chegam, para identificar os elementos sobre os quais nós decidimos - agir, organizar nossas intervenções, finalizar um conjunto de atividades, a partir de uma representação que toamos do "real"? (MEIRIEU, 1987, p. 164 apud LAURENS, 2012, p. 60, tradução nossa, grifos do autor).

Laurens (2012) destaca ainda que o processo de modelagem das Sequências capacita o professor e, estendemos ao pesquisador a:

[...] fazer escolhas, por exemplo, sobre os objetivos a serem trabalhados, os documentos para privilegiar, os tipos de atividades a serem selecionadas, a ordem para realizá-las, as técnicas de motivação a serem usadas, etc., seja no momento do planejamento da ação ou no momento da realização da ação planejada (LAURENS, 2012, p. 60).

No campo da Didática da Matemática, há uma gama de teorias que possibilitam a construção de Sequências Didáticas, como a Teoria das Situações Didáticas (TSD) de Brousseau (1986, 1996); a Dialética-FerramentaObjeto de Regine Douady (1984); o Registro de Representação Semiótica de Raymond Duval (2003); a Teoria Antropológica do Didático (TAD), de Yves Chevallard (1999, 2009a); a Teoria dos Campos Conceituais de Vergnaud (1996). Neste artigo, enfocaremos o modelo oriundo da TSD, com algumas indicações da TAD.

\section{ENCAMINHAMENTOS PARA UMA ACEPÇÃO ESPECÍFICA DE SEQUÊNCIA DIDÁTICA}

Para o encaminhamento do modelo da TSD como estruturante de Sequências didáticas, realizamos um levantamento de alguns modelos propostos por pesquisadores franceses, que no nosso entender se configuram como um discurso de construção de Sequências, atendido pela TSD.

Noverraz (2016) desenvolveu um modelo que descreve as distintas fases de uma Sequência Didática, para auxiliar professores em treinamento das áreas de Ciências e Matemática, na construção de suas primeiras sequências, mas que podem servir para professores experientes que 
precisem clarificar os contratos didáticos que regem as experiências de seus alunos. Assim, o autor postula três fases principais constitutivas de uma sequência: fase de imersão e familiarização contextual; fase de conceituação e descontextualização e fase de reinvestimento (exploração e recontextualização) (Quadro 1).

Quadro 1 - Modelo Didático das Três Fases de uma Sequência Didática

\begin{tabular}{|c|c|}
\hline FASE & DESCRIÇÃO \\
\hline $\begin{array}{l}\text { Fase da Imersão e } \\
\text { familiarização } \\
\text { contextual }\end{array}$ & $\begin{array}{l}\text { Trata-se de uma fase experiencial, com objetos e } \\
\text { fenômenos. A fim de envolver os discentes em um } \\
\text { contexto de iniciação científica no qual está em jogo a } \\
\text { aquisição do saber-fazer para reativar ou desenvolver } \\
\text { conhecimentos e habilidades necessárias futuramente. }\end{array}$ \\
\hline $\begin{array}{c}\text { Fase da } \\
\text { Conceitualização e } \\
\text { descontextualização }\end{array}$ & $\begin{array}{l}\text { A fase de conceituação é central na sequência. Nela o } \\
\text { professor dá tarefas aos alunos que criam necessidades } \\
\text { cognitivas: estudo de caso, enigmas, projeto de } \\
\text { realização, projetos de comunicação, situações- } \\
\text { problemas. O professor coloca os alunos em situações que } \\
\text { lhes permitirão formular questões. Diante da tarefa, os } \\
\text { alunos fazem conjecturas, buscam informações, } \\
\text { experimentam, desenvolvem estratégias, desenvolvem } \\
\text { modelos. O professor desempenha interações sociais na } \\
\text { sala de aula, provoca o debate. } \\
\text { Esta fase termina com a institucionalização } \\
\text { (sistematização) dos objetos em estudo, mesmo que a } \\
\text { teoria em jogo tenha validade local. }\end{array}$ \\
\hline Fase de reinvestimento & $\begin{array}{l}\text { A última fase da sequência é a que dá ao aluno a } \\
\text { oportunidade de praticar e testar o conhecimento } \\
\text { construído em contextos novos ou até expandidos. Nessa } \\
\text { fase, as competências desenvolvidas nas fases anteriores } \\
\text { devem ser mobilizadas é o momento que suscita a } \\
\text { avaliação formativa, mesmo estando presente em todo o } \\
\text { processo (três fases) aqui o docente certifica-se da } \\
\text { apropriação do saber, visto que o aluno encontra-se } \\
\text { frente a novos problemas e desafios. Esse é propício para } \\
\text { que o aluno faça uma análise crítica de como resolver um } \\
\text { determinado problema. }\end{array}$ \\
\hline
\end{tabular}

Fonte: Adaptado de Noverraz (2016).

O autor assegura que três fases não estão isoladas, mas que são articuladas em atividades de transições que ele demonina fases intermediárias.

Por sua vez, Rickenmann (1998) enfatiza que o modelo de uma sequência deve contemplar: 
Um tema que indique aos alunos um domínio de aplicação dos conhecimentos pesquisados, assim como, disponibilize sistemas simbólicos que permita o trabalho nesse domínio, a partir de procedimentos conhecidos que possam ser mobilizados pelos alunos na atividade; um objetivo bem definido para atividade 0 contrato didático ${ }^{7}$ deve possibilitar ao aluno ter a expectativa que a situação adidática ${ }^{8} \circ$ possibilitará vislumbrar um novo conhecimento; o objetivo traz consigo o saber a ensinar esse não deve ser revelado ao aluno no tramite da situação a-didática, pois é, precisamente, o conhecimento que deve ser mobilizado para solucionar a questão posta aos alunos, vale ressaltar que para facilitar o trabalho do professor é necessário que esse estruture o milieu ${ }^{9}$ (materiais, instrumentos, procedimentos, recursos, etc.); as variáveis didáticas possibilitam a análise do milieu em particular sua dimensão material, para identificar os elementos que irão incentivar $O$ discente a mobilizar os saberes a ensinar. A idenficicação das variáveis durante o enfrentamento da tarefa permite inventariar as estratégias de ação do estudante, ou seja, a forma ou formas de resolver a tarefa; O Milieu: constitui uma parte importante do meio adidático, o milieu é identificado pelos alunos não só como material, instrumento ou procedimento, mas também, como uma prática social de referência10; Instruções: trata-se da definição do quadro e das regras da

\footnotetext{
7 Denomina-se contrato didático o conjunto de comportamentos do professor que são esperados pelos alunos e o conjunto de comportamentos do aluno que são esperados pelo professor [...] Esse contrato é o conjunto de regras que determinam uma pequena parte explicitamente, mas ,sobretudo, implicitamente, do que cada parceiro da relação didática deverá gerir e daquilo que, de uma maneira ou de outra, ele terá de prestar conta perante o outro. (BROUSSEAU, 2008, p. 21).

8 A situação adidática é parte essencial da situação didática, é uma situação na qual a intenção de ensinar não é revelada ao aprendiz, mas foi imaginada, planejada e construída pelo professor/pesquisador para proporcionar a esses, condições favoráveis para a apropriação do novo saber que se deseja ensinar (ALMOULOUD, 2010).

9 Segundo Brousseau (1996) o aluno aprende sobre um ou mais objetos adaptando-se a um milleu (ou meio) fator de contradições, de dificuldades, de desequilíbrios. Assim o aluno poderá ir avançando por meio de atividades organizadas em Sequências Didáticas.

10 Segundo Rickenmann (1998) a prática social de referência é um elemento fundamental na estruturação de sequências didáticas. Esta noção é assumida pelo autor tal como definida por Geertz (1986). Considera-se nessa perpectiva que todo saber é parte de um sistema semiótico-pragmático, ou seja, o significado ou significados que pode transportar um objeto de saber estão intimamente ligados ao uso cultural do mesmo objeto. Por conseguinte, a sensação de um objeto de saber depende fundamentalmente da área de
} 
atividade. Para o professor, contribui para a objetivação da estruturação da sequência (tempos, procedimentos, limites, etc.). Para o estudante, a instrução indica que o quadro geral da atividade (objetivos, meios) e as regras de interação com 0 milieu. Avaliação: Para o professor, a identificação dos saberes a ensinar e suas articulações com os objetivos da atividade (especialmente durante o desenvolvimento da atividade), ajudam a identificar indícios, para determinar no curso da atividade o estado de progresso do aluno em relação aos seus próprios objetivos.

No campo das Ciências Astolfi (1990) examina diversas possibilidades de comando em Sequências Didáticas, analisando as influências de distintos aportes teóricos na fundamentação da construção dessas (de forma explícita ou implícita). Nessa perspectiva, são analisados modelos pedagógicos construtivistas e sócioconstrutivistas.

Assim, esse autor distinguiu quatro modos de orientações para uma sequência: seja por uma Situação a Explorar; um Método para Dominar; um Saber a Adquirir ou um Obstáculo a Superar. Astolfi ressalta que esses modos não são excludentes e podem ser combinados para uma melhor eficácia da sequência, assim como não abrangem somente a área de ciências e particularmente de Geologia, mas também, outras áreas como Matemática, Linguagem, etc. Vejamos com mais detalhes cada uma das categorias com direcionamento para algumas noções matemáticas, mais especificamente referentes a noções de divisibilidade, mais especificamente relativo aos números primos e compostos.

\section{Sequência comandada pela exploração de uma situação}

De acordo com Astolfi (1990), as situações atreladas às sequências dessa categoria podem estar relacionadas a um grande número de conceitos, mas que não são abordados na íntegra, e sim, de forma parcial ou introdutória. Tais situações podem ser retomadas em momentos oportunos, de acordo com objetivos futuros do professor em aprofundar, 
sistematizar, institucionalizar, etc. os conceitos em jogo, ou seja, não se trata de uma introdução geral de diferentes aspectos de uma noção. Podemos assumir os níveis de codeterminação didática ${ }^{11}$, para melhor compreensão de como uma sequência pode tratar de um objeto específico, como por exemplo, uma situação em que se trabalhe o crivo de Eratóstenes para explorar a noção de números primos e compostos.

Tal situação não permite analisar efetivamente o conceito de número primo, sua infinidade, etc., mas ao mesmo tempo, apresenta potencial para explorar futuramente as noções de múltiplos, divisores, máximo divisor comum e mínimo múltiplo comum, assim como o teorema fundamental da aritmética. Além do estudo estrito dos primos, em níveis mais avançados como na graduação.

\section{Sequências comandadas pela busca de aquisição do saber}

Como na categoria anteriormente vista, a sequência apresenta exemplos como ponto de partida, mas, desde o início, está subordinada ao domínio de uma determinada noção. Em outras palavras, os exemplos não são estudados com fim em si próprios, como no caso anterior, em que não se explorava os diversos aspectos dos conceitos envolvidos, pois não havia objetivo de concretizar um determinado conceito.

A função dos exemplos apresentados difere substancialmente da do caso anterior. Pode ser do tipo de exemplos motivacionais (para "ancorar" a sequência sobre os interesses e preocupações dos alunos), ou do tipo referencial (para "âncora" em experiência anterior, o local, o já conhecido), os dois aspectos se combinam facilmente na prática. Isso significa que esses exemplos são direcionados ao mesmo tempo para concretizar a introdução de conceitos (podemos falar de exemplos paradigmáticos) e para verificar se eles funcionam de forma operatória para os alunos. (ASTOLFI, 1990, p. 167, tradução nossa, destaques do autor).

\footnotetext{
11 Bosch e Gascón (2009) e Chevalard (2002, 2009a) destacam que a Teoria Antropológica do Didático (TAD) - como extensão da Teoria da Transposição Didática - propõe que nas instituições ocorre uma hierarquia de níveis de determinação (ou codeterminação) entre as organizações matemáticas (OM) escolares e as correspondentes organizações didáticas (OD), esta hierarquia é estruturada mediante uma sucessão de níveis que determinam as mútuas dependências entre as OM e OD. Civilização $\leftrightarrow$ Sociedade $\leftrightarrow$ Escola $\leftrightarrow$ Pedagogia $\leftrightarrow$ Teoria $\leftrightarrow$ Área $\leftrightarrow$ Setor $\leftrightarrow$ Tema $\leftrightarrow$ Objeto
} 
Nesse tipo de sequência, são trabalhados exemplos diversificados que podem inclusive, retomar uma situação como a da categoria anterior. Pode ser necessário, por vezes, mudar de exemplo no decorrer da atividade, caso perceba que sequência recaíra estritamente na primeira categoria, na qual, o estudo da noção em jogo poderá ser parcial, mesmo sendo desejável que se explore uma situação como a anterior, como ponto de partida (o Crivo de Eratóstenes), mas com a obrigação de maior abrangência, ou seja, indo além do estudo de um objeto em particular, chegando à exploração de um tema (divisibilidade) ou mesmo de um setor (Teorema Fundamental da Aritmética), da disciplina que agregam várias noções para apropriação (como números primos, compostos, múltiplos, divisores, etc.).

\title{
Situação comandada pela busca do domínio de um método
}

Nesta categoria está em jogo à "apropriação de um método científico de análise, que é proposto aos alunos ou construído com eles" (ASTOLFI, 1990, p. 167). As apropriações de noções referentes à disciplina em estudo terão papel secundário,

\begin{abstract}
O que permite distinguir esse tipo de Sequência da anterior parece ser seu regime de contrastes de interações didáticas. Quando é "o método que comanda", então cada proposição do aluno é - de maneira equivalente - ouvida, discutida e finalmente validada ou refutada, graças precisamente ao uso desta ferramenta que fornece - método que está sendo apreendido (observação, experimentação, medição...). Quando, pelo contrário, é o estabelecimento de uma noção que "comanda", vemos o método eleito imposto pelo professor... E isso é compreensível porque não damos a palavra aos estudantes exatamente pelos mesmos motivos em ambos os casos. No primeiro, as interações didáticas obedecem sobre tudo a um "modo dedutivo", toda proposição ou resposta do aluno sendo examinada a partir do duplo ponto de vista de suas consequências, como suas conexões lógicas com os elementos anteriormente anunciados. No segundo, operamos sobre tudo de "modo a regulativo", as proposições feitas pelos alunos permitem ao professor certificar-se de que o método é conceitualmente seguido e fornecendo-lhe um "retorno ativo" para guiá-lo em sua progressão. (ASTOLFI, 1990, pp. 167-168, tradução nossa, grifo do autor).
\end{abstract}

Nesta categoria de sequência, há um ritmo mais lento no desenvolvimento das atividades, em razão de se objetivar nessas ações que favoreçam o engajamento dos alunos, em procedimentos experiências, 
quando eles precisam resolver um problema científico, no qual podemos ter como parâmetro, procedimentos canônicos estabelecidos ao longo do tempo, pela área de conhecimento a qual a sequência se insere como comparar, medir, separar variáveis, emitir e verificar hipóteses (ASTOLFI, 1990).

Para ilustrar uma sequência com essas características podemos nos apoiar em Chevallard (2004), Chevallard e Ladage (2010), ao se referir à Pedagogia da Investigação - método fundamentado num ponto de vista Antropológica - nessa perspectiva, o saber não é dado a priori, como normalmente acontece nas aulas de matemática, mas emerge com a função de responder uma dada questão problemática, que favoreça a entrada dos alunos num processo de estudo. Esse método foi efetivado nas escolas de Ensino Secundário francês, por meio de Sequências Didáticas, organizadas em torno de Atividades de Estudo e Pesquisa (AEP) e/ou do Percurso de Estudo e Pesquisa (PEP), esse último dispositivo apresenta configuração similar ao primeiro, mas demanda um tempo maior, pois o PEP requer um conjunto de AEP (CHEVALLARD, 2009a e 2009b; BARACHET; DEMICHEL; NOIRFALISE, 2007).

Em ambos os casos (AEP e PEP), a dinâmica de funcionamento segue - modelo denominado por Chevallard de momentos didáticos, que se configuram por meio do primeiro encontro - momento que abre o processo de estudo, mais, precisamente, um encontro com as tarefas $T$, constitutivas de uma Organização Matemática (OM) - conforme a ideia de Situação Fundamental, cunhada por Guy Brousseau; o momento exploratóriol2 referente à construção de uma técnica adequada para abordar a tarefa dada; o momento constitutivo do ambiente tecnológico-teórico, no qual se busca justificação da prática matemática em jogo, esse momento está em estreita inter-relação com cada um dos outros momentos, visto que essa constituição vem se moldando desde o primeiro encontro. O quarto

\footnotetext{
12 Assim, nasce uma dialética fundamental: o estudo de problemas é um meio pertinente de criar e desenvolver uma técnica relacionada aos problemas do mesmo tipo, uma técnica que, em si, será o meio de resolver problemas desse tipo de forma quase rotineira (CHEVALLARD, 1999, p. 244).
} 
momento é o do trabalho da técnica, busca-se tornar eficaz a técnica e aperfeiçoar a tecnologia desenvolvida até esse momento; é o momento em que se coloca em xeque a técnica em um conjunto de tarefas adequadas. O quinto momento é o momento da institucionalização, nele se define a organização matemática, a qual se destina o estudo, no decorrer dos momentos anteriores, constitui-se uma história singular que, agora assume estatuto universal pertencente à cultura que abriga a gênese do saber em questão, assim oficializa-se o saber. O sexto momento é o da avaliação que se articula ao momento da institucionalização; nas palavras de Chevallard (1999, p. 246):

\begin{abstract}
A operação de avaliação deve ser entendida em um sentido mais amplo: para além da avaliação clássica das relações pessoais, isto é, para além da avaliação de "pessoas", é delineada a avaliação da própria norma - do relacionamento institucional que serve como um padrão. Quanto vale, de fato, a organização matemática que foi construída e institucionalizada? [...] encontramos então o interrogatório sobre a própria técnica - é poderosa, gerenciável, segura, robusta também? Esta avaliação - a qual as escolas concedem, é verdade, uma parte muito pequena - formadora, não de uma pessoa, mas de uma praxeologia: desse ponto de vista, participa da institucionalização. Como elemento reformador, permite relançar o estudo, suscita a reposição desse ou aquele momento, e talvez de todo o trajeto didático.
\end{abstract}

Trata-se de um processo de modelagem matemática, que leve 0 discente a encontrar elementos que possibilite dar resposta a uma dada questão. Nessa perspectiva, podemos, por exemplo, solicitar para que os discentes investiguem quais os modelos algébricos que geram números múltiplos de dois e três; ou envolve-los num processo de conjecturas sobre modelos para gerar números primos (pode-se investigar a conjectura de Goldbach).

\title{
Sequências comandadas pela busca de superação de obstáculos
}

O estudo dos obstáculos está relacionado ao estudo dos erros, seja no âmbito da filosofia das Ciências (BACHELLARD, 1996) ou no ensino da Matemática (BROUSSEAU, 1983). Nesse sentido, Pinto (2000) assevera que existem três possíveis alternativas teóricas para se estudar o erro no processo 
de ensino e aprendizagem: a psicogenética, a epistemológica e a sociológica. Na perspectiva psicogenética, o erro é baseado nas contribuições dos estudos de Piaget; na perspectiva epistemológica baseiase na noção de obstáculos de Bachelard (1996), cujo direcionamento para matemática foi dado por Brousseau (1983, 1986, 1998); já a perspectiva sociológica traz em si o antagonismo representado entre o sucesso e o fracasso escolar, na tentativa de diminuir o antagonismo entre as classes sociais ou pelo menos não serem reproduzidas na escola.

Astolfi (1990, p. 169) refere-se à perspectiva epistemológica e chama atenção para necessidade de identificação de obstáculos pelos professores, pois, a partir dessa constatação poderão organizar sequências específicas que possibilitem a superação desses.

É para um obstáculo deste tipo que uma sequência pode ser direcionada. Mas isso requer uma condição: que o mestre, dependendo dos elementos que ele dispõe relativo ao nível da turma e dos alunos, considere realista o "salto conceitual" demandado. Porque, substancialmente diria Bachelard, "um obstáculo continua a ser um obstáculo" e não pode ser ultrapassado "na força", a menos que pareça já enfraquecido, "rachado", e que o objetivo da sequência seja acelerar e sistematizar uma evolução percebida. As sequências anteriores comandadas, por uma situação ou por uma noção, no curso da qual a presença de um obstáculo foi objeto de um primeiro "rastreamento" nos alunos (se não tivesse sido precisamente analisado), pode ter sido a ocasião para avaliação de possibilidades didáticas.

Segundo Brousseau (1983), o erro é a expressão, ou a manifestação explícita, de um conjunto de percepções espontâneas, ou reconstruídas, que, integradas a uma rede coerente de representações cognitivas, tornamse obstáculo à aquisição e ao domínio de novos conceitos. Deste modo, o professor precisa intervir efetivamente na aprendizagem de nossos alunos visando à superação desses obstáculos.

Como diz Brousseau, o saber não pode avançar mascarado, e o mestre é levado a criar todas as peças de uma situação didática ad hoc, subordinada à superação programada do obstáculo. Tal situação uma espécie de construção calculada, e opõe-se fortemente a situações mais imediatas, previsto no primeiro parágrafo, como extensão de senso comum. Então, pode-se explicar a introdução aqui do Termo da situação didática, em contraste com 
as situações pedagógicas do primeiro caso. (ASTOLFI, 1990, p. 169, tradução nossa, destaques do autor).

Para Brousseau (2008, p. 21) "uma 'situação' é um modelo de interação de um sujeito com um meio determinado", para o sujeito que aprende enfrentar uma dada situação requer conhecimentos já apropriados, pelo menos para iniciar a resolução e outros conhecimentos devem ser mobilizados para aquisição de novos conhecimentos.

No começo da década de 70 , as situações didáticas eram "aquelas que serviam para ensinar sem que fosse levado em conta o papel do professor", ou seja, para transmitir um determinado conhecimento utilizavamse "meios" (textos, material etc.).

A situação era, portanto, o contexto que cercava o aluno, projetado e manipulado pelo professor, que a considerava uma ferramenta. Posteriormente, identificamos como situações matemáticas todas àquelas que levam o aluno a uma atividade matemática sem a intervenção do professor. Reservamos o termo situações didáticas para os modelos que descrevem as atividades do professor e do aluno (BROUSSEAU, 2008, p. 21).

A noção de Situação Didática ganhou complexidade no interior da Teoria das Situações Didáticas (TSD), idealizada por Guy Brousseau que a define como um:

[...] conjunto de relações estabelecidas explicitamente e/ou implicitamente entre um aluno ou grupo de alunos, um certo milieu (contendo eventualmente instrumentos ou objetos) e um sistema educativo (o professor) para que esses alunos adquiram um saber constituído ou em constituição. (BRAOUSSEAU, 1978 apud ALMOULOUD, 2010, p. 33).

Assim, a TSD constitui-se um modelo para analisar o processo de ensino e aprendizagem, assim como construir Sequências Didáticas. Tal modelo teórico decompõe-se em quatro tipos de situações distintas, que potencializam um processo de investigação em sala de aula, nas quais o saber tem funções diferentes e o aprendiz não estabelece a mesma relação com esse. Nestas situações interligadas, podem-se observar tempos 
dominantes de ação, de formulação, de validação e de

institucionalização ${ }^{13}$ (Quadro 2):

\section{Quadro 1 - Etapas de uma sequência didática concebida à luz da TSD*}

\begin{tabular}{|c|c|}
\hline $\begin{array}{c}\text { Situação de } \\
\text { Ação }\end{array}$ & $\begin{array}{l}\text { Esta é a primeira etapa da sequência, planejada como um } \\
\text { desafio para os alunos assumirem e se envolverem no processo } \\
\text { de estudo'14, as respostas dos alunos serão predominantemente } \\
\text { experimentais, sem grandes influências teóricas. As ações são } \\
\text { ancoradas em conhecimentos já estabelecidos, mas que não } \\
\text { permitem a compreensão sistemática do objeto em estudo. Por } \\
\text { exemplo, usar a situação clássica do crivo de Eratóstenes para } \\
\text { explorar as noções de sequências numéricas que mais tarde } \\
\text { favorecerão a compreensão de múltiplos, divisores, números } \\
\text { primos, etc. A organização da sequência deve possibilitar ao } \\
\text { aluno (individualmente ou em grupo) enfrentar o problema sem } \\
\text { intervenção direta do professor. }\end{array}$ \\
\hline $\begin{array}{l}\text { Situação de } \\
\text { Formulação }\end{array}$ & $\begin{array}{l}\text { A partir das ações desenvolvidas na etapa anterior da } \\
\text { sequência o aluno poderá produzir uma solução mais } \\
\text { elaborada, a partir de elementos de alguma teoria, mas sem a } \\
\text { intenção explícita de validação ou justificação da resposta. A } \\
\text { partir da atividade anterior propomos outra na qual se anuncie } \\
\text { que as sequências numéricas construídas representam múltiplos, } \\
\text { por exemplo, do primeiro número da sequência e que esse é } \\
\text { divisor dos subsequentes, em seguida, solicitamos a clássica } \\
\text { questão do crivo, referente a eliminação dos múltiplos. Depois } \\
\text { requeremos aos discentes que escrevam determinados números } \\
\text { na forma de produto de primos. Todo o processo se desenvolve } \\
\text { com intensa comunicação das ideias, como requer o processo } \\
\text { de investigação. }\end{array}$ \\
\hline $\begin{array}{l}\text { Situação de } \\
\text { Validação }\end{array}$ & $\begin{array}{l}\text { Na comunicação de ideias iniciada na etapa anterior o } \\
\text { professor conduz os discursos para um processo que busque } \\
\text { validar as soluções para um grupo ou toda a turma; uma prova }{ }^{15} \\
\text { que comprove uma determinada explicação particular; ou até } \\
\text { mesmo uma demonstração, como um tipo particular de prova } \\
\text { em matemática. Como no caso de solicitarmos justificativas } \\
\text { para a escrita dos compostos presentes na tabela poderem ser } \\
\text { escrito na forma de produto de primos. }\end{array}$ \\
\hline $\begin{array}{c}\text { Situação de } \\
\text { Institucionalização }\end{array}$ & $\begin{array}{l}\text { Nessa etapa o professor interfere diretamente visando } \\
\text { estabelecer um caráter de universalidade e objetividade do } \\
\text { conhecimento, sintetizando-o e ligando-o a outros } \\
\text { conhecimentos. Assim, o conhecimento novo produzido pelo } \\
\text { aluno torna-se socialmente aceito, conferindo-lhe um tipo de } \\
\text { validade cultural, onde há um diálogo entre professores e alunos } \\
\text { sobre conhecimentos matemáticos historicamente construídos }\end{array}$ \\
\hline
\end{tabular}

13 As três primeiras etapas são consideradas por Brousseau como Situação adidática a terceira como didática.

14 Brousseau (2008, p. 91) define que devolução é o ato pelo qual o professor faz com que o aluno aceite a responsabilidade de uma situação de aprendizagem (adidática) ou de um problema e assume ele mesmo as consequências dessa transferência. E esse ato apresenta grandes dificuldades que são analisadas tradicionalmente à luz de teorias cognitivistas que tratam da motivação do aluno.

15 Balacheff (1987) 


\begin{tabular}{|l|l|}
\hline & $\begin{array}{l}\text { relativos, por exemplo, aos números, primos e compostos e ao } \\
\text { Teorema Fundamental da Aritmética. }\end{array}$ \\
\hline
\end{tabular}

Fonte: Adaptado de Rocha et al. (2013).

* As etapas anunciadas não são rígidas, pelo contrário, muitas das vezes ocorrem de forma concomitante.

Constatamos que a TSD, e mais particularmente, as Situações que modelam a construção das Sequências, contemplam os itens elencados por Rickenmann (1998), como necessários a composição dessas.

A Figura 1 representa um momento de ação diante um milieu antagonista onde, podemos constatar que ocorre a interação inicial entre o sujeito e o meio, que leva ao encontro do aluno com a situação que deve provocar a devolução e o estabelecimento do contrato didático, configurando-se o momento de ação.

Figura 1 - Esquema de uma situação de ação

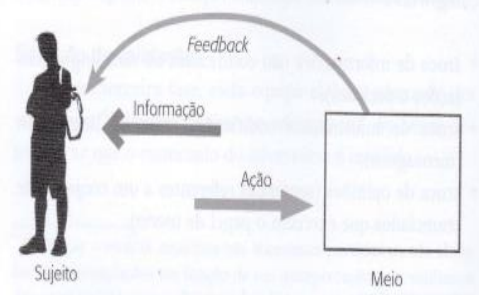

Fonte: Brousseau (2008, p. 28)

Constatamos que no modelo de Noverras (2016), a Situação de Ação apresenta semelhanças com a Fase da Imersão e familiarização contextual, visto que em ambas está em jogo a apropriação de um saber-fazer como princípio fundamental.

Brousseau explica o esquema da Figura 2 da seguinte forma:

O repertório dos modelos implícitos de ação e o modo como se estabelecem são muito complexos. Podemos supor, com base nas ideias de Bateson, que a formulação de um conhecimento implícito muda, ao mesmo tempo, suas possibilidades de tratamento, aprendizagem e aquisição. A formulação de um conhecimento corresponderia a uma capacidade do sujeito de retomá-lo (reconhecê-lo, identifica-lo, decompô-lo e reconstruí-lo em um sistema linguístico). O meio que exigirá do sujeito o uso de uma formulação deve, então, envolver (efetivamente ou de maneira fictícia) um outro sujeito, a quem o primeiro deverá comunicar uma informação. Dessa forma, pode-se descrever a situação usando o esquema de Osgood (1957). (BROUSSEAU, 2008, p. 29). 
Figura 2 - Esquema de uma situação de formulação

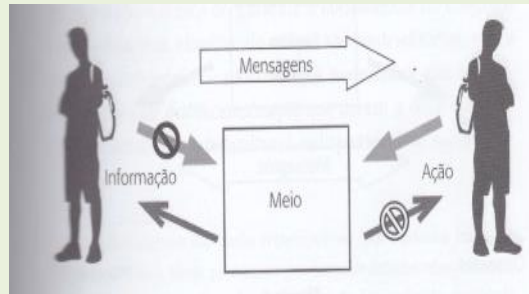

Fonte: Brousseau (2008, p. 29)

Assim como em Noverras (2016), na Fase da Conceitualização e descontextualização igualmente os alunos trocam ideias entre si e com o professor. Há uma intensa comunicação que possibilita o uso de argumentos e contra argumentos, com a mediação mínima do professor o meio deve provocar as ações.

A Figura 3 representa que a troca de ideias do momento anterior deve levar a uma solução coletiva, aceita pela comunidade de estudo, estabelecida para o enfrentamento da situação. $O$ que leva à comunicação à turma de uma resposta acolhida por um grupo ou mesmo por um único sujeito. Também guarda similaridades com a Fase da Conceitualização e descontextualização propostas por Noverras (2016).

Figura 3 - Esquema de uma situação de validação

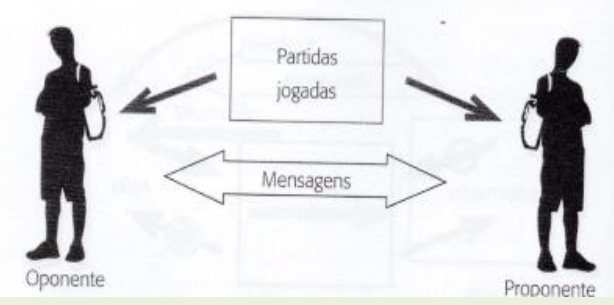

Fonte: Brousseau (2008, p. 30)

A Situação adidática compõe um espectro maior que é o da Situação Didática que congrega a primeira (Situação adidática), a Situação de Institucionalização, definida como aquela em que o professor fixa convencionalmente e explicitamente o estatuto cognitivo do saber. Uma vez 
construído e validado, o novo conhecimento vai fazer parte do patrimônio matemático da classe, embora não tenha ainda o estatuto de saber social:

Se feita muito cedo, a institucionalização interrompe a construção do sentido, impedindo uma aprendizagem adequada e produzindo muitas dificuldades para o professor e para os alunos. Se for feita muito tarde, reforça interpretações errôneas e dificulta a aprendizagem e aplicações (ALMOULOUD; MANRIQUE; SILVA; CAMPOS, 2004, p. 98).

Após a institucionalização, feita pelo professor, o saber torna-se oficial e os alunos devem incorporá-lo a seus esquemas mentais, tornando-o assim, disponível para utilização na resolução de problemas matemáticos.

Assim como na fase de reinvestimento de Noverras (2016), Brousseau (1996) afirma que o aprendizado se evidencia quando o aluno aplica o que apreendeu em outro contexto. No decorrer da Sequência, o discente se apropria de um conhecimento no interior de um contextual especifico, para mudar o estatuto de conhecimento personalizado e contextualizado, a Situação de Institucionalização se apresenta com a função de despersonalizar e descontextualizar o saber em jogo que, assim está apto para um (re)investimento em outros contextos.

Com respeito à construção de Sequências no seio da Didática da Matemática devemos ressaltar duas questões basilares, uma referente à metodologia, que deve traçar os caminhos para essa construção (via Engenharia Didática), outra referente a referente a Situação Fundamental, ponto de partida da Sequência em particular naquelas concebidas à luz da TSD e TAD.

Para conceber uma Sequência Didática, no âmbito da Didática da Matemática, assume-se em geral a Metodologia da Engenharia Didática que apresenta as seguintes etapas:

1. Análises preliminares: considerações sobre o quadro teórico didático geral e os conhecimentos já adquiridos sobre o assunto em questão, incluem a análise epistemológica do ensino atual e seus efeitos, das concepções dos alunos, dificuldades e obstáculos, e análise do campo das restrições e exigências no qual vai se situar a efetiva realização didática. 
2. Concepção e análise a priori das situações didáticas: o pesquisador, orientado pelas análises preliminares, delimita certo número de variáveis pertinentes ao sistema sobre os quais o ensino pode atuar, chamadas de variáveis de comando (microdidáticas ou macrodidáticas). [...]

3. Experimentação: consiste na aplicação da sequência didática, tendo como pressupostos apresentar os objetivos e condições da realização da pesquisa, estabelecer o contrato didático e registrar as observações feitas durante a experimentação.

4. Análise a posteriori e validação: A análise a posteriori consiste em uma análise de um conjunto de dados colhidos ao longo da experimentação, como por exemplo, produção dos alunos, registros de observadores e registro em vídeo. Nessa análise, se faz necessário sua confrontação com a análise a priori para que seja feita a validação ou não das hipóteses formuladas na investigação. (ALMOULOUD; SILVA, 2012, pp, 26-27, grifos dos autores).

Com o avanço das pesquisas nesse campo, a engenharia comporta, hoje em dia, outras características conforme se apresente como Engenharia de Primeira Geração, referida anteriormente, cuja principal autora foi Artigue (1988), Engenharia de Segunda Geração, como descrita por Perrin-Glorian (2009); Engenharia dos Domínios de Experiência, conforme apresenta Boero (2009) ou Engenharia didática de Percurso de Ensino e Pesquisa (PEP) desenvolvida por Chevallard (2009b).

As situações de ação, formulação e validação estão engendradas por uma situação fundamental segundo Brousseau (1986, p. 49) apud Almouloud (2010, p. 34).

[...], cada conhecimento pode ser caracterizado por, pelo menos, uma situação adidática que preserva seu sentido e que é chamada de situação fundamental. Ela determina o conhecimento ensinado a um dado momento e o significado particular que esse conhecimento vai tomar do fato tendo em vista as escolhas das variáveis didáticas e as restrições e reformulações sofridas em seu processo de organização e reorganização (ALMOULOUD, 2010, p. 34).

Almouloud (2010, p. 34) ao analisar o exposto anteriormente, conclui que uma situação fundamental constitui um grupo restrito de situações adidáticas, cuja noção a ensinar é a resposta considerada a mais adequada/indicada, essas situações permitem introduzir os conhecimentos em sala de aula numa epistemologia propriamente científica.

Outra definição sobre a situação fundamental é de Perrin-Glorian (1999) que afirmou que:

Revista Exitus, Santarém/PA, Vol. 9, № 1, p. 148 - 174, JAN/MAR 2019. 
A situação fundamental é uma situação adidática característica de um saber (saber correspondendo às situações de validação) ou de um conhecimento (conhecimento correspondente às situações de ação). Os diferentes valores dados às variáveis didáticas da situação devem permitir gerar todas as situações representativas dos diferentes sentidos ou diferentes ocasiões de emprego do saber em jogo. (ALMOULOUD, 2010, p. 34).

Com respeito à noção de Situação Fundamental Legrand (1993, p. 124) registrou o seguinte:

Uma situação será fundamental se ela:

- tiver por sua consistência epistemológica e sua adaptação ao campo conceitual do aluno, o poder de modificar o conformismo escolar;

- permitir uma desestabilização e justificar a aceitação de uma mudança de ponto de vista, que deve então favorecer os conflitos da racionalidade:

- permitir a devolução do projeto global do saber.

Podemos afirmar que ao conhecer cada tipo de situação de ensino é possível intervir da melhor forma possível no processo de ensino e aprendizagem de uma sequência, através de escolhas cada vez mais pertinentes, analisando as variáveis que vão se apresentando, sejam as que temos ciência ou as que não.

\section{CONSIDERAÇÕES FINAIS}

O objetivo deste artigo foi trazer à tona as discussões recentes em torno da noção de Sequência Didática em particular na perspectiva da Didática da Matemática. Ressaltamos o crescente interesse por essa noção em pesquisas em nível estricto sensu.

Em nossas reflexões evidenciamos os encaminhamentos teóricos e metodológicos para construção das Sequências e vislumbramos mais estritamente a TSD como modelo de consecução dessas, com alguns indicativos do potencial da TAD como modelo geral para conceber uma Sequência.

Assim esperamos ter contribuído para uma melhor compreensão de construção e funcionamento desse dispositivo didático, tanto para sua 
aplicação em sala de aula, quanto em pesquisas científicas. Além do potencial como dispositivo de formação inicial e continuada de professores da escola básica.

Buscamos também, mostrar como essa noção se desenvolveu no seio das escolas francesas e as diferentes indicações para construção das Sequências, assim, revelamos como essas se configuram no modelo da TSD.

Uma das grandes vantagens que percebemos a respeito do uso desse dispositivo didático e de formação foi seu potencial para, como postula Brousseau (1996), de levar o aluno a um trabalho intelectual, por momentos, comparável a uma atividade científica, ou seja, o aluno age como um investigador sobre as Sequências problemáticas que o professor/pesquisador Ihe propõe que solucione. Pois bem sabemos que, para se apropriar de conhecimentos, em particular matemáticos, não basta aprender definições e teoremas; e sim resolver problemas dos quais ele possa "agir, formular, provar, construir modelos, linguagens, conceitos, teorias, os troque com outros, reconheça aquelas que são mais conformes à cultura, retire desta, aqueles que Ihe são úteis, etc." (BROUSSEAU, 1996, p. 70).

Nesse sentido, cabe ao professor estabelecer uma relação epistemológica com os objetos matemáticos que the possibilite construir Sequências Didáticas, que recontextualizem o saber científico, como propõe Brousseau, simulando uma micro sociedade científica. Consabido que o saber escolar atinja o status que nos postula Brousseau, além disso, deve também proceder de maneira que não forneça a resposta aos discentes levando o aluno a aprender, adaptando-se ao milieu. Mas tem também, de dar aos seus alunos meios para descobrirem, nessa história particular que os fez viver, aquilo que é o saber cultural e comunicável que se pretendeu ensinar-Ihes. Trata-se evidentemente, de uma simulação, que não é a verdadeira atividade científica, da mesma maneira que 0 saber apresentado de forma axiomática não é o verdadeiro saber. 


\section{REFERÊNCIAS}

ALMOULOUD, S. A.; MANRIQUE, A. L.; M. J. F. SILVA; T. M. M. CAMPOS. A geometria no ensino fundamental: reflexões sobre uma experiência de formação envolvendo professores e alunos Revista Brasileira de Educação. n.27, pp.94-108, 2004.

ALMOULOUD, S. A. Fundamentos da didática da matemática. Curitiba: UFPR, 2010.

ALMOULOUD, S. A.; SILVA. M. J. F. Engenharia didática: evolução e diversidade. Revista Eletrônica De Educação Matemática. v. 7, n. 2, 2012.

ARTIGUE, M. Ingénierie Didactique. Recherches en Didactique des Mathématiques. Grenoble: La Pensée Sauvage-Éditions, v. 9.3, p. 281-308, 1998.

ARTIGUE, M. L'ingénierie didactique: un essai de synthèse. in Margolinas et all.(org.): Em amont et en aval des ingénieries didactiques, $X V^{a}$ École d’Été de Didactique des Mathématiques - Clermont-Ferrand (PUY-de-Dôme).

Recherches em Didactique des Mathématiques. Grenoble: La Pensée Sauvage, v. 1, p. 225-237, 2009.

ASTOLFI, J. P. Quelques Logiques de Construction D'une Séquence D'apprentissage En Sciences: L'exemple de la géologie à l'école élémentaire. ASTER, n. 13, pp. 157-186, 1991.

BACHELARD, G. A formação do espírito científico. São Paulo: Contraponto, 1996.

BALACHEFF, N. Processus de preuves et situations de validation. Educational Studies in Mathematics, v. 18, n. 2, p. 147-176, 1987.

BARACHET, F.; DEMICHEL, Y.; NOIRFALISE, R. Activites D'etude et de Recherche (AER) Pour Dynamiser L'etude de la Geometrie dans L'espace en Classe de Seconde Françoise. IREM de Clennont-Ferrand. Petit x. v. 75, p. 34-49, 2007.

BLACK, P.; WILLIAM, D. Assessment and classroom learning In: Assessment in Education: Principles, Policy \& Practice. mar 1998, vol.5, Issue 1.

BOERO, P. Les domaines d'expérience dans l'enseignement - Apprentissage des mathématiques: Lier le travail scolaire a l'experience des eleves, in Margolinas et all.(org.) : En amont et en aval des ingénieries didactiques, XVa École d'Été de Didactique des Mathématiques - Clermont-Ferrand (PUY-deDôme). Recherches em Didactique des Mathématiques. Grenoble: La Pensée Sauvage, v. 1, p. 111-148, 2009.

BOSCH, M.; GASCÓN, J. Aportaciones de la Teoría Antropológica de lo Didáctico a la formación del profesorado de matemáticas de Secundaria. In: 
González, M. J., González, M. T.; Murillo, J. (Eds.) Investigación en Educación Matemática XIII. (pp. 89-113), 2009.

BROUSSEAU, G. Les obstacles épistémologiques et les problèmes en mathématique. Recherches en Didactique des Mathématiques, 1983. Vol. 4, No. 2, pp. 165-198.

BROUSSEAU, G. Fondements et méthodoes de la Didactique des Mathématiques. Recherches en Didactique des Mathématiques, Grenoble: La Pensée Sauvage-Éditions, 1986. v.7.2, pp.33-115.

BROUSSEAU, G. Théorisation des phénomènes d'enseignement des mathématiques. Thèse d'état, Université de Bordeaux I, 1986.

BROUSSEAU, G. Théorie des situations didactiques. Textes rassemblés et préparés par Nicolas Balacheff, Martin Cooper, Rosamund Sutherland, Virginia Warfield. Grenoble: la Pensée Sauvage Éditions, 1998. Col. Recherches en didactiques des mathématiques.

BROUSSEAU, G. Fundamentos e métodos da didática da matemática In: Didáctica das matemáticas, Direção: Jean Brun. Coleção horizontes pedagógicos; Instituto Piaget, Lisboa, 1996.

BROUSSEAU G. Epistemologia e Formazione Degli Insegnanti. In: BROUSSEAU, G., Ingegneria Didattica ed Epistemologia della Matematica, p. 51-56. Pitagora Editrice, Bologne, 2006.

BROUSSEAU, G. Introdução ao Estudo das Situações Didáticas: Conteúdos e Métodos de Ensino. São Paulo: Ática, 2008.

CHEVALLARD, Y. L’analyse des pratiques enseignantes en théorie anthopologique du didactique, Recherches en didactiques des mathématiques. Grenoble. La pensée Sauvage Éditions, v. 19.2, p. 221-265, 1999.

CHEVALLARD, Y.; BOSCH, M.; GASCÓN, J. Estudar matemáticas: o elo perdido entre o ensino e a aprendizagem. Tradução: Daisy Vaz de Moraes. Porto Alegre: Artmed, 2001.

CHEVALLARD, Y. Organiser l'étude 3. Écologie \& régulation. In: DORIER, J.-L.; ARTAUD, M.; ARTIGUE, M.; BERTHELOT R.; FLORIS, R. (Ed.) Actes de la 11 e école de didactique des mathématiques. Grenoble: La Pensée Sauvage, 2002. p. 41-56.

CHEVALLARD, Y. Vers une didactique de la codisciplinarité. Notes sur une nouvelle épistémologie scolaire. Texte préparé en vue d'une communication aux Journées de didactique comparée 2004 (Lyon, 3-4 mai 2004). Version retouchée du 19 mai 2004. Disponivel em 
<http://yves.chevallard.free.fr/spip/spip/article.php3?id_article=45>. Acesso em: 24 abr. 2016.

CHEVALLARD. Y. La TAD face au professeur de mathématiques. 2009 a. Disponível em:

<http://yves.chevallard.free.fr/spip/spip/article.php3?id_article=162>. Acesso em: 24 abr. 2016.

CHEVALLARD, Y. La notion d'ingénierie didactique, un concept à refonder. Questionnement et élémentos de réponses à partir de la TAD. in Margolinas et all.(org.): Em amont et en aval des ingénieries didactiques, $X V^{a}$ École d'Été de Didactique des Mathématiques - Clermont-Ferrand (Puy-de-Dôme).

Recherches em Didactique des Mathématiques. Grenoble: La Pensée Sauvage, v. 1, p. 81-108, 2009b.

CHEVALLARD, Y.; LADAGE, C. Clinique et ingénierie de l'enquête codisciplinaire: un atelier "Enquêtes sur Internet" au collège. Communication au Ille Congrès international sur la théorie anthropologique du didactique, Sant Hilari Sacalm, Catalogne, 25-29, 2010.

\section{DOUADY, R. Jeux dês cadres et dialectique outil-objet dans l' enseigne,ent} dês mathématiques. Thèse de Doctorat d'Etat (specialité didactique dês mathématiques). Paris, Université Paris VII, 1984.

DUVAL, R. Registro de representações semióticas e funcionamento cognitivo da compreensão em matemática. In: Aprendizagem em Matemática: registro de representação semiótica. Organização de Silvia Dias Alcântara Machado, p 11- 33, Campinas, São Paulo: Papirus, 2003.

LAURENS, V. Modéliser des séquences en FLE et FLM : analyse comparée de I'unité didactique et de la séquence didactique ", Le français aujourd'hui, n¹76, 2012, pp. 59-75.

LEGRAND, L. A pedagogia do projecto. In: Trabalho de projectos: leituras comentadas. 3. ed. Portugal: Edições Afrontamento, 1993. (coleção Ser Professor) p. 36-39.

NOVERRAZ. Modèle didactique des trois phases d'une séquence d'enseignement. Didactique des sciences HEP. 2016. Encontrado em: https://www.bdrp.ch/document-pedagogique/les-trois-phases-dunesequence-denseignement-0

NUNES, R. S. Números Primos e a Constituição do MMC e MDC. Dissertação (Mestrado). Programa de Pós-Graduação em Educação em Ciências e Matemáticas. Universidade Federal do Pará, 2017.

PERRIN-GLORIAN, M. J. L'ingénierie didactique a l'interface de la recherche avec l'enseignement. Développement des ressources et formação des enseignants. In: MARGOLINAS, et al.(org.): En amont et en aval des 
ingénieries didactiques, $X V^{a}$ École d'Été de Didactique des Mathématiques Clermont-Ferrand (PUY-de-Dôme). Recherches em Didactique des

Mathématiques. Grenoble: La Pensée Sauvage, v. 1, p. 57-78, 2009.

PINTO, N. B. O erro como estratégia didática: estudo do erro no ensino da matemática elementar. Campinas, SP: Papirus, 2000.

RICKENMANN, R. Modèle de structure de la séquence didactique. 1998.

<http://www.unige.ch/fapse/SSE/teaching/uf713/mise-oeuvre.html>. Acesso em março de 2016.

VERGNAUD, G. A Teoria dos Campos Conceituais In: Didáctica das

matemáticas, Direção: Jean Brun. Coleção horizontes pedagógicos; Instituto Piaget, Lisboa, 1996.

ZABALA, A. A Prática educativa. Trad. Ernani F. da F. Rosa. Porto Alegre: ArtMed, 1998.

Recebido em: 07 de janeiro de 2018 Aprovado em: 30 de outubro de 2018 